\title{
Comparative Study of One-Step Cross-Linked Electrospun Chitosan-Based Membranes
}

\author{
Yanet E. Aguirre-Chagala, ${ }^{1}$ Laura B. Pavón-Pérez, ${ }^{1}$ Víctor Altuzar, ${ }^{2}$ \\ Jorge G. Domínguez-Chávez, ${ }^{3}$ Severino Muñoz-Aguirre, ${ }^{2}$ and C. Mendoza-Barrera ${ }^{2}$ \\ ${ }^{1}$ Laboratorio de Nanobiotecnología, MICRONA, Universidad Veracruzana, 94294 Boca del Río, VER, Mexico \\ ${ }^{2}$ Facultad de Ciencias Físico-Matemáticas, Benemérita Universidad Autónoma de Puebla, 72570 Puebla, PUE, Mexico \\ ${ }^{3}$ Facultad de Bioanálisis, Universidad Veracruzana, 91700 Veracruz, VER, Mexico
}

Correspondence should be addressed to C. Mendoza-Barrera; cmendoza_barrera@hotmail.com

Received 3 March 2017; Revised 27 May 2017; Accepted 5 June 2017; Published 6 July 2017

Academic Editor: Russell E. Gorga

Copyright (C) 2017 Yanet E. Aguirre-Chagala et al. This is an open access article distributed under the Creative Commons Attribution License, which permits unrestricted use, distribution, and reproduction in any medium, provided the original work is properly cited.

\begin{abstract}
Chitosan membranes are widely applied for tissue engineering; however, a major drawback is their low resistance in aqueous phases and therefore the structure collapses impeding their long-term use. Although there is extensive research, because of chitosan's importance as a biomaterial, studies involving chitosan-based membranes are still needed. Herein, a detailed investigation of diverse chemical routes to cross-link fibers in situ by electrospinning process is described. In case of using genipin as crosslinker, a close relationship with the content and the mean diameter values is reported, suggesting a crucial effect over the design of nanostructures. Also, the physical resistance is enhanced for the combination of two types of methods, such as chemical and physical methods. Cross-linked fibers upon exposure to long wave ultraviolet A (UVA light) change their morphology, but not their chemical composition. When they are incubated in aqueous phase for 70 days, they show an extensive improvement of their macrostructural integrity which makes them attractive candidates for tissue engineering application. As a result, the thermal properties of these materials reveal less crystallinity and higher temperature of degradation.
\end{abstract}

\section{Introduction}

The extracellular matrix (ECM) provides structural framework for tissues and biochemical support to the surrounding cells; among its most important functions are cell adhesion, proliferation, migration, and cellular recognition [1]. All these processes are located in the ECM microarchitecture, which in general is organized in fibrillary arrangements with large interstitial interconnected spaces. As a result of the complexity of the ECM, a diversity of matrices have been manufactured, whose properties should mimic the native extracellular matrix as nearly as possible $[2,3]$. In an attempt to overcome this subject, a variety of natural and synthetic polymers have been used $[4,5]$. The electrospinning technique is an easy, feasible, and scale-up method to process this type of materials, in order to fabricate fibers at nano- and microscale closely resembling the ECM structure. Electrospinning technology consists in placing a polymer solution in a metal capillary where it is driven out, creating an elongated polymeric jet by applying an electrical field, whose fibers are collected on a grounded collector in a specific diameter and mesh form $[6,7]$.

Nowadays, chitosan $(\mathrm{CH})$ has been thoroughly studied and applied in tissue engineering, creating a vast number of composites with synthetic polymers to tailor its properties $[8$, 9]. It is a linear polysaccharide obtained by partial deacetylation of chitin from the exoskeleton (shells) of the crustaceans (such as scabs and shrimps), cell walls of fungi, and yeasts, the second most abundant natural polymer in nature $[4$, 10]. Their chemical structure is composed of a randomly distributed $\beta$-(1,4)-linked $\mathrm{N}$-acetyl-D-glucosamine and $\mathrm{D}$ glucosamine units; this polycationic polymer has biological, physical, and chemical properties, making it one of the most recurrent and attractive biomaterials in the fabrication of scaffolds [11]. Because of the presence of the amine and hydroxyl groups, chitosan provides a platform to attach side 
groups and interact with other biological molecules [12]. In addition, chitosan has demonstrated antimicrobial activity and inhibits the growth of fungi and bacteria, and it also displays biocompatibility and biodegradability; these unique characteristics bring it closer to obtaining a desired biomaterial with required properties for biomedical engineering [13, 14]. Despite the well-known advantages of any biopolymer, being electrospun successfully into scaffolds, such biomaterials as chitosan, because of being hydrophilic in nature, still present challenges with respect to its physical stability. Regarding chitosan's hydrophilic character, this property is associated with promoting fiber dissolution, leading to an insufficient resistance in aqueous conditions and poor mechanical firmness to resist handling during biological tests; such issue is crucial for biomedical applications. For the purpose of avoiding these identified problems, it has been resorted to methods such as cross-linking and the blending with other polymers with better mechanical properties. Cross-linking is a common method to increase the stability of biomaterials in simulated body fluid (SBF), phosphate buffer saline (PBS), and diluted acetic acid $[2,11,15,16]$. In this context, different cross-linking methods can be performed in order to enhance the fiber stability, such as chemical method through covalent bonds [17], ionic method by electrostatic interactions, and physical method by exposing ultraviolet (UV) light [18]. Cross-linking can tailor the biodegradation rate, the mechanical strength, and biological properties [19, 20]; however, the use of chemical cross-linkers sometimes produces side effects on the biological response, derived from the exceeded limit of the molecule cross-linker content and/or free harmful materials exposed to the cells attachments. For this reason, it is important to consider the minimum amount of synthetic exogenous chemicals.

Chitosans have free amine functionalities; a bifunctional compound must be coupled by covalent attachment towards amine groups [21]. Genipin (GNP) is a natural compound isolated from the hydrolysis of geniposide that is extracted from the fruits of the plant Gardenia jasminoides Ellis that can serve as an excellent cross-linker for proteins and chitosan $[22,23]$. In addition, other cross-linker as glutaraldehyde (GTA) can react with chitosan amine groups, which may occur either via Michael-type adduct by binding with aldehyde end-groups and/or through Schiff bases leading to imine functionality [24]. For instance, exposure of GTA vapor onto the chitosan/PEO matrices improves the structural integrity [25], without using any cross-linker method, the polymeric mat dissolves instantly, while GTA cross-linked mats in acidic, neutral, and basic medium resisted, taking more time and having a better ability to absorb water [2628]. Biological studies with chitosan cross-linked with GTA have demonstrated cytotoxicity. On the contrary, GNP crosslinked chitosan materials have showed good biocompatibility towards human RPE cells and low acute toxicity in vivo $[21,29]$, making them more suitable for regeneration of tissues [29-33]. Meanwhile, GTA cross-linked chitosan fibers triggered apoptosis at earlier stage on cells. The potential cytotoxicity may be caused by the interaction of the available aldehyde groups of the unreacted GTA in the scaffold [21]. The aim of this study is to investigate the cross-linked fiber morphologies by incorporating distinct cross-linkers; the latter results were achieved by assessing the stability of the nanofibers. We focused particularly on the most promising method and coupling reagent to fabricate nontoxic and physicochemical stable polymer-based scaffold, potentially useful for tissue engineering applications.

\section{Experimental}

2.1. Materials. Poly(ethylene oxide) (PEO, $M_{w}=600,000 \mathrm{~g} /$ mol), chitosan medium molecular weight $\left(\mathrm{CH}, M_{w}=\right.$ $190,000-310,000 \mathrm{~g} / \mathrm{mol}$, deacetylation degree $=75-85 \%)$, glutaraldehyde (GTA solution, $50 \% \mathrm{w} / \mathrm{v}$ in $\mathrm{H}_{2} \mathrm{O}$ ), sodium tripolyphosphate technical grade, $85 \%$ (TPP), genipin $\geq$ 98\%(GNP), 2,2-dihydroxyindane-1,3-dione (ninhydrin (NHD)), and hexamethylenediamine (HMDA) were obtained from Sigma-Aldrich. Acetic acid was purchased from J. T. Baker and used as received. Deionized water was purified in a Barnstead Nanopure system.

2.2. Preparation of Cross-Linked Chitosan/Poly(ethylene oxide) Fibers. Firstly, $0.06 \mathrm{~g}$ of chitosan was added slowly in $10 \mathrm{~mL}$ of $10 \%(\mathrm{v} / \mathrm{v})$ acetic acid solution and dissolved. Subsequently, $0.24 \mathrm{~g}$ of $\mathrm{PEO}$ was incorporated under vigorous stirring and was dissolved at room temperature, where the weight polymer ratio was kept constant to $\mathrm{PEO} / \mathrm{CH}=80 / 20$ for all solutions, with a total polymer weight of $0.3 \mathrm{~g}(3 \% \mathrm{w} / \mathrm{v})$. Then, the solution was sealed and allowed to dissolve for above $24 \mathrm{~h}$. After that, to cross-link the fibers in situ either of these following reagents GTA, TPP, or GNP was transferred through a micropipette in the polymer solution, in order to target $0.1,0.3$, and $0.5 \% \mathrm{v} / \mathrm{v}(1: 136,1: 45$, and $1: 27$ as mol GTA : mol $\mathrm{NH}_{2}$ ratio, resp.) in case of GTA and 0.1 , 0.3 , and $0.5 \% \mathrm{v} / \mathrm{v}$ for TPP $(1: 83,1: 28$, and $1: 17$ as mol TPP : $m o l \mathrm{NH}_{2}$ ratio, resp.); for GNP case, polymer solutions containing $0.1,0.2,0.3,0.4$, and $0.5 \% \mathrm{v} / \mathrm{v}(1: 51,1: 25,1: 17$, $1: 13$, and $1: 10$ as mol GNP:mol $\mathrm{NH}_{2}$ ratio, resp.) were prepared from a $6.25 \mathrm{mg} / \mathrm{mL}$ genipin solution in $10 \%(\mathrm{v} / \mathrm{v})$ ethanol. The final solution was sealed and dissolved for 2 more hours. For electrospinning process, relative humidity and temperature were monitored with Labview Software. The glovebox was degassed with nitrogen, where $30-35$ relative humidity percent was kept constant at room temperature. Then, the polymer solution was transferred into a syringe with a caliber stainless steel needle of $21 \mathrm{G} \times 32 \mathrm{~mm}$ and then placed onto a programmable injection pump (KD Scientific ${ }^{\mathrm{TM}}$, model: 780100V), located next to the glovebox. The needle tip was connected to the anode of the voltage power supply (Gamma High Voltage Research, model: ES60p-20W/DAM) and the cathode was attached to a $12 \mathrm{~cm} \times 12 \mathrm{~cm}$ aluminum sheet as a collector. The injection rate was of $1 \mathrm{~mL} / \mathrm{h}$, the applied voltage was ranging within $24-27 \mathrm{kV}$, and the needle distance to the collector was kept constant to $12 \mathrm{~cm}$. Finally, fibers were stored in a desiccator for further analysis.

\subsection{Preparation of GNP Cross-Linked/Poly(ethylene oxide)} Fibers under UVA Irradiation. Another experiment group of solutions was prepared at the same concentrations of GNP, $0.1,0.2,0.3,0.4$, and $0.5 \% \mathrm{v} / \mathrm{v}\left(4.419 \times 10^{-3}, 8.83 \times 10^{-3}\right.$, 


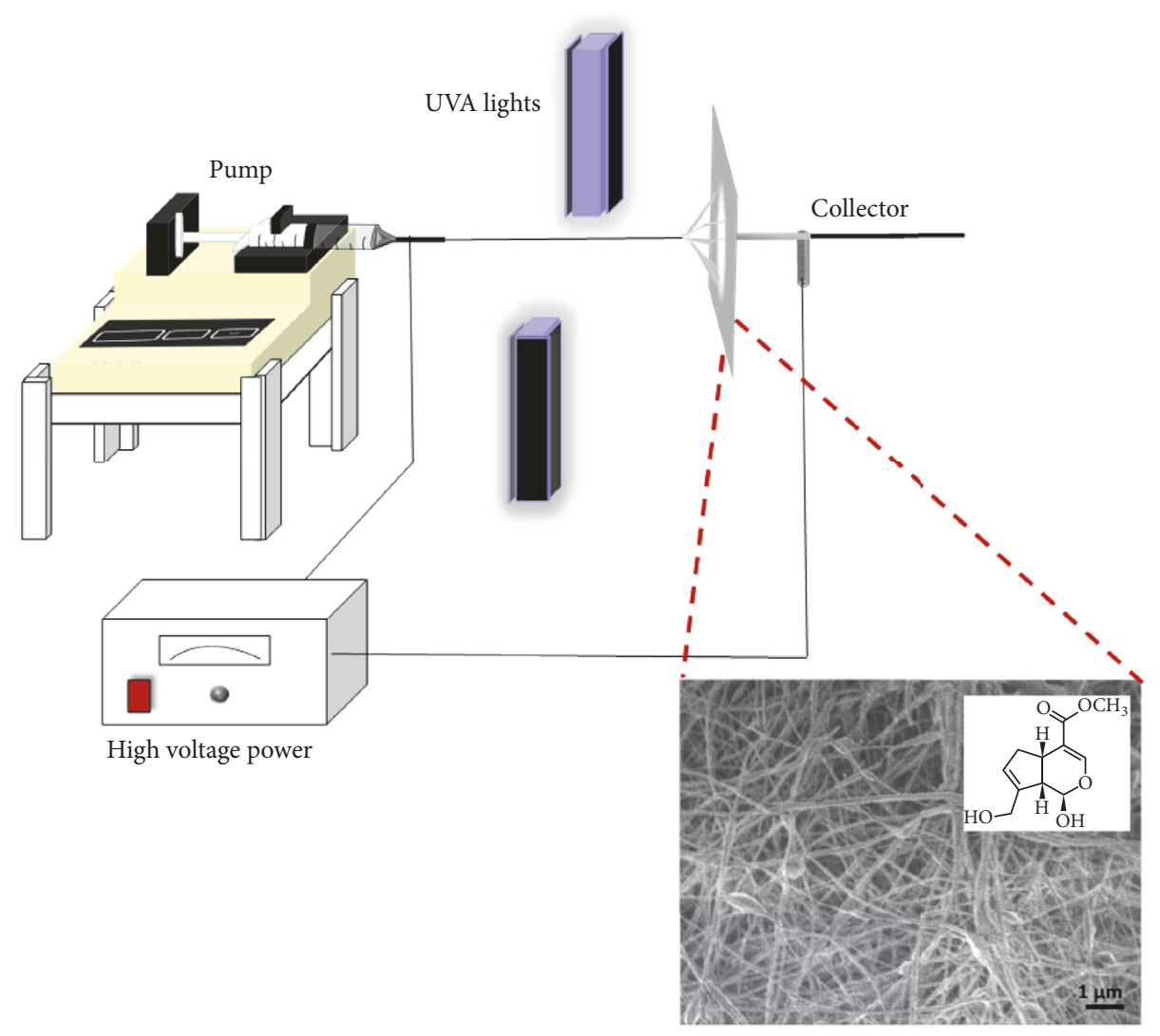

SCHEme 1: Cross-linking process during electrospinning technique.

$0.0132,0.0176$, and $0.0625 \mathrm{mmol}$ GNP added, resp.), but with applying UVA irradiation with two lamps of 6 watts $(366 \mathrm{~nm}$ wavelength, Figures S2 and S4 in Supplementary Material available online at https://doi.org/10.1155/2017/1980714) during the electrospinning process (see Scheme 1), where they both were placed by each side at midpoint between the syringe and the collector. Each sample was labeled and stored for further assessments.

2.4. Swelling Behavior. The study was determined by the immersion of $1 \mathrm{~cm}^{2}$ of the dried membranes in PBS $10 \mathrm{mM}$, $\mathrm{pH}$ 7.4. At a certain time, the swollen samples were withdrawn and blotted gently with a wipe and the weight was registered. The swelling percent $\left(\% S_{w}\right)$ was determined from the following expression:

$$
\% S_{w}=\frac{W_{w}-W_{d}}{W_{d}} \times 100,
$$

where $W_{d}$ and $W_{w}$ indicate the weights of the dried and swollen samples, respectively.
2.5. Cross-Linking Efficiency. The ninhydrin analysis method was employed to quantitatively detect the amount of $-\mathrm{NH}_{2}$ groups on $\mathrm{PEO} / \mathrm{CH}$ matrices [35]. Approximately $5 \mathrm{mg}$ of each membrane was placed in a microcentrifuge vial and $100 \mu \mathrm{L}$ of ninhydrin solution $32 \mathrm{mM}$ in ethanol was added, followed by heating at $70^{\circ} \mathrm{C}$ for 30 minutes in a water bath to accelerate the reaction between ninhydrin and amino groups on membranes displaying blue color [21]. Immediately, all vials were uncapped to allow the evaporation of ethanol. Then $700 \mu \mathrm{L}$ of a mixture of water/isopropanol $(75 / 25 \mathrm{v} / \mathrm{v})$ was added to prepare the solution by using the vortex for a certain amount of time [36]. The supernatant was taken out and placed in another microcentrifuge vial through a micropipette. Right after, the final solution was placed in a cuvette and the absorbance measured at $570 \mathrm{~nm}$ by UV-vis spectrophotometer. The solid was dried and weighed, and the part resuspended was estimated and used to calculate the final concentration of chitosan measured by UV-vis. A standard curve was previously prepared using solutions of known 1,6diaminohexane concentrations (Figure S1). The cross-linking efficiency (\% CE) was estimated from the following:

$$
\begin{aligned}
\% \mathrm{CE} & =\frac{\text { total free } \mathrm{NH}_{2} \text { before crosslinking }- \text { free } \mathrm{NH}_{2} \text { after crosslinking }}{\text { total free } \mathrm{NH}_{2} \text { before crosslinking }} \times 100 \\
& =\frac{\text { mmol } \mathrm{NH}_{2} / \mathrm{mg} \mathrm{CS} \text { before crosslinking }- \text { mmol NH} / \mathrm{mg} \mathrm{CS} \mathrm{after} \mathrm{crosslinking}}{\mathrm{mmol} \mathrm{NH}_{2} / \mathrm{mg} \mathrm{CS} \text { before crosslinking }} \times 100,
\end{aligned}
$$


TABLE 1: Summary of cross-linked fiber diameter data obtained from SEM micrographs.

\begin{tabular}{|c|c|c|c|c|}
\hline Membrane & Cross-linker reagent & Cross-linker content $(\% \mathrm{v} / \mathrm{v})$ & mol GNP : $\mathrm{mol} \mathrm{NH}_{2}$ & Fiber diameter $(\mathrm{nm})$ \\
\hline S0.1GTA & GTA & 0.1 & $1: 136$ & $144 \pm 40$ \\
\hline S0.3GTA & GTA & 0.3 & $1: 45$ & $159 \pm 91$ \\
\hline S0.5GTA & GTA & 0.5 & $1: 27$ & $147 \pm 35$ \\
\hline S0.1TPP & TPP & 0.1 & $1: 83$ & $132 \pm 68$ \\
\hline S0.3TPP & TPP & 0.3 & $1: 28$ & $119 \pm 49$ \\
\hline S0.5TPP & TPP & 0.5 & $1: 17$ & $133 \pm 61$ \\
\hline S & - & 0.0 & - & $131 \pm 41$ \\
\hline S0.1GNP & GNP & 0.1 & $1: 51$ & $119 \pm 33$ \\
\hline S0.2GNP & GNP & 0.2 & $1: 25$ & $91 \pm 24$ \\
\hline S0.3GNP & GNP & 0.3 & $1: 17$ & $86 \pm 25$ \\
\hline S0.4GNP & GNP & 0.4 & $1: 13$ & $80 \pm 29$ \\
\hline S0.5GNP & GNP & 0.5 & $1: 10$ & $58 \pm 17$ \\
\hline SUV & UVA & 0 & - & $98 \pm 20$ \\
\hline S0.1GNPUV & GNP+UVA & 0.1 & $1: 51$ & $95 \pm 28$ \\
\hline S0.2GNPUV & GNP+UVA & 0.2 & $1: 25$ & $91 \pm 33$ \\
\hline S0.3GNPUV & GNP+UVA & 0.3 & $1: 17$ & $56 \pm 12$ \\
\hline S0.4GNPUV & GNP+UVA & 0.4 & $1: 13$ & $108 \pm 26$ \\
\hline S0.5GNPUV & GNP+UVA & 0.5 & $1: 10$ & $107 \pm 30$ \\
\hline
\end{tabular}

where total free $\mathrm{NH}_{2}$ before cross-linking is $0.06262 \mathrm{mmol}$ $\mathrm{NH}_{2} / \mathrm{mg}$ CS.

2.6. Characterization. Images of the electrospun composites were obtained with a JEOL model JSM-7600F scanning electron microscope; samples were prepared by placing a conductive carbon double-sided tape. The voltage used was $0.5 \mathrm{kV}$, and $\times 30,000, \times 20,000, \times 10,000, \times 5,000$, and $\times 1,000$ magnification was used to analyze all samples. The fiber diameter distribution was determined using Image ${ }^{\circledR}$ Software, by measuring 100 fibers for each one. FT-IR spectra were recorded on a Thermo Scientific spectrometer (model Nicolet Isso FT-IR) with ATR apparatus, in the $4000-500 \mathrm{~cm}^{-1}$ range, with a resolution of $4 \mathrm{~cm}^{-1}$ and 32 scans per minute. Thermal properties were recorded by differential scanning calorimetry (DSC) Q2000 TA Instruments, with a heating rate of $10^{\circ} \mathrm{C} / \mathrm{min}$ from 25 to $200^{\circ} \mathrm{C}$. Thermogravimetric analysis (TGA) was performed using Q50 TA Instruments. Samples were heated from 25 to $600^{\circ} \mathrm{C}$ with a heating rate of $10^{\circ} \mathrm{C} / \mathrm{min}$ under nitrogen atmosphere; around $6 \mathrm{mg}$ of sample was weighted for DSC and TGA analysis.

2.7. Statistical Analysis. Data were analyzed by one-way analysis of variance (ANOVA) in conjunction with Tukey's post hoc test for multiple comparisons. Differences were considered with significant at $p<0.05$.

\section{Results and Discussion}

3.1. Morphological Analysis. In this study, cross-linked fibers were made in situ in the polymer solution by coupling reactive groups onto pendant amino side groups of the chitosan. To develop a simple chemical approach to produce cross-linked fibers in the best conditions, a morphological analysis with three different chemical reagents was carried out, as a comparative purpose. Prior to evaluating the ability to cross-link the fiber, our research group previously examined the spinnability of $\mathrm{PEO} / \mathrm{CH}$ solution, by preparing a group of polymeric scaffolds upon 30-35\% relative humidity, stablishing adequate atmospheric parameters in order not to impact on the surface morphology and merely to study the influence of the cross-linked process.

GTA cross-linked fibers presented smooth surface in the majority of the nanocomposite at $0.1,0.3$, and $0.5 \% \mathrm{v} / \mathrm{v}$ $\left(1: 136,1: 45\right.$, and $1 \mathrm{~mol} \mathrm{GTA}: 27 \mathrm{~mol} \mathrm{NH}_{2}$, resp.) (Figures 1(a), 1(b), and 1(c)), yielding nanoscale sizes of $144 \pm 40 \mathrm{~nm}$ (Table 1). In contrast, TPP cross-linked fibers displayed beads at any concentration (Figures 1(d), 1(e), and 1(f)); a possible explanation for this is the mechanism of ionotropic gelation during solution preparation, since the whole process is highly $\mathrm{pH}$-dependent; the protonated amino and ionic groups underwent quick interaction giving chitosan-TPP gel $[36,37]$. The solutions were prepared under acidic condition at $\mathrm{pH} 2.26$, suitable to deprotonate the glucosamino moieties onto chitosan and to promote the ionic gelation. It has been reported that chitosan fibers have high degree of crosslinking at $\mathrm{pH} 3$ of $\sim 85 \%$ [36], close to the $\mathrm{pH}$ used in our protocol. Charged phosphates groups $\left(\mathrm{P}_{3} \mathrm{O}_{4}{ }^{5-}\right)$ of TPP interact with the positively charged amino groups of chitosan, serving as ionic cross-linker by the electrostatic interaction of charged species $[38,39]$. Although, at $0.5 \% \mathrm{v} / \mathrm{v}$, TPP $(1 \mathrm{~mol}$ TPP : $17 \mathrm{~mol} \mathrm{NH}_{2}$ ) was incorporated, the morphology was sufficient to produce coagulation in the solution. It is caused by the influence of the faster ionotropic gelation between the ionic species, creating less capability of the spinnability in the solution. As a consequence of this type of mechanism, the network formation occurred at an earlier stage generating physical entrapment of polymer molecules in the network 


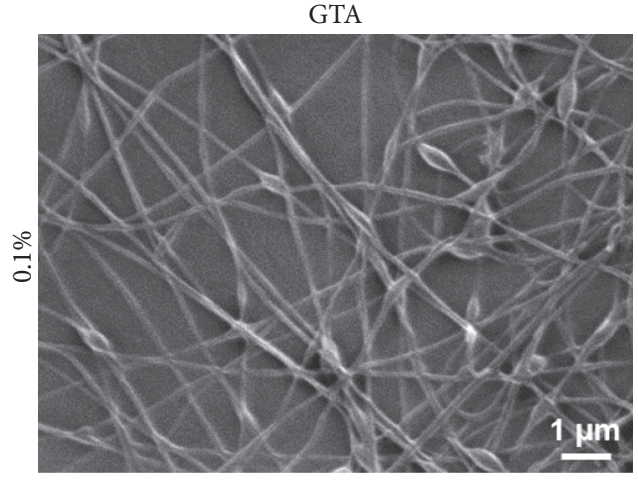

(a)



(b)



(c)

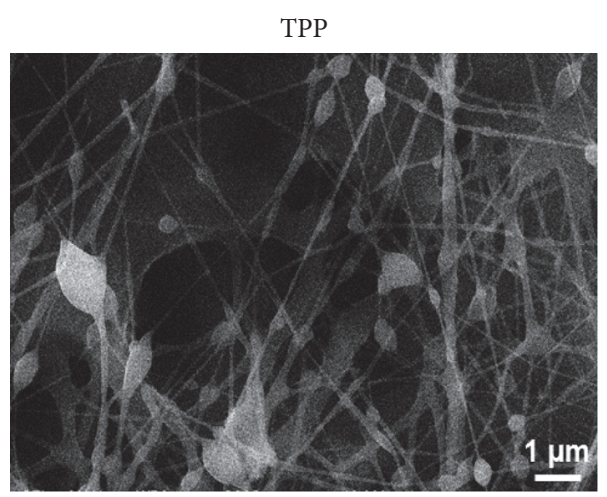

(d)

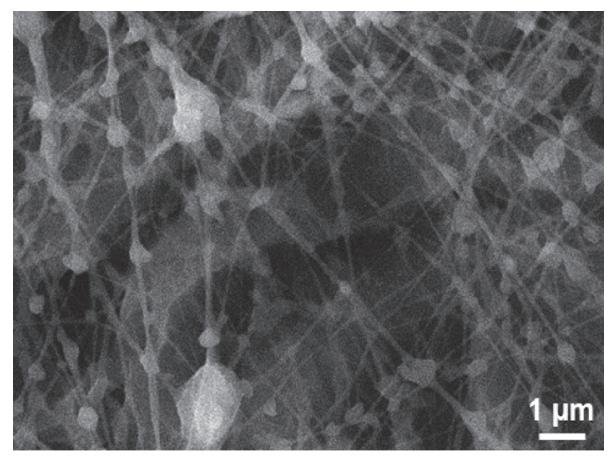

(e)



(f)

Figure 1: SEM images of the cross-linked S (PEO/CH) fibers at $0.1,0.3$, and $0.5 \% \mathrm{v} / \mathrm{v}$ of GTA or TPP. Scale bars in the inset image correspond to $1 \mu \mathrm{m}, \times 10,0000.5 \mathrm{kV}$.

freshly formed in the solution that impeded uniform width along jet, and consequently beads were formed during the electrospinning [40]. On the other hand, covalent coupling takes longer reaction times than ionic interactions, thereby allowing the reduction of beads by other routes besides crosslinking. In this sense, a kinetic chemistry perspective is an important element to determine the viability of the fiber formation.

Morphology results indicated that both genipin and glutaraldehyde did not alter greatly the spinnability of the polymer solution during the electrospinning with a fairly fiber formation, exhibiting better morphology than TPP [41]. Taking this characteristic into account, producing one-step cross-linked fibers importantly reduces the number of stages during the scaffold manufacture.
Genipin is an excellent natural bifunctional cross-linker and it is a water-soluble molecule that has been applied to proteins, collagen, gelatin, and chitosan. Also, it has a lower acute toxicity than glutaraldehyde and was selected as a possible biocompatible cross-linker for $\mathrm{S}(\mathrm{PEO} / \mathrm{CH})$ fibers $[29,33,42,43]$. Because of this argument, we will largely focus on GNP cross-linked fibers for later analysis. GNP cross-linked fibers were then prepared at 0.1, 0.2, 0.3, 0.4, and $0.5 \% \mathrm{v} / \mathrm{v}(1: 51,1: 25,1: 17,1: 13$, and $1 \mathrm{~mol} \mathrm{GNP}: 10 \mathrm{~mol}$ $\mathrm{NH}_{2}$, resp.) in acidic environment like the other ones, which favor the ring-opening mechanism that will be discussed in another section. Representative micrographs are shown in Figure 2, where we can observe the surface morphologies. Particularly at $0.1 \% \mathrm{v} / \mathrm{v}$ of GNP ( $1 \mathrm{~mol}$ GNP : $51 \mathrm{~mol} \mathrm{NH}_{2}$ ) (Figure 2(b)), the presence of nanofibers and very few beads 




(a)

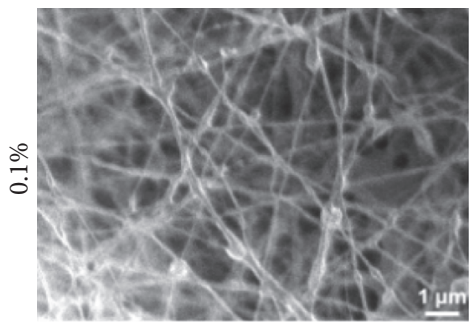

(b)

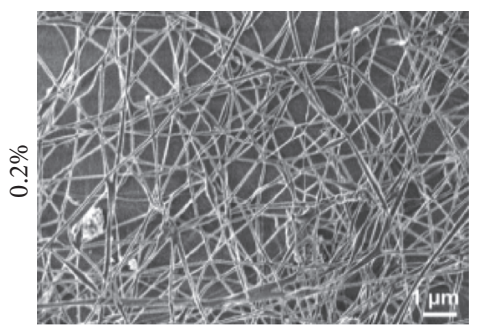

(c)



(d)

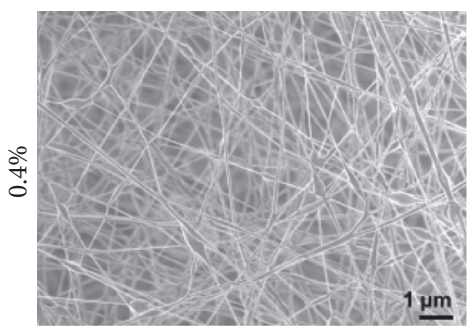

(e)

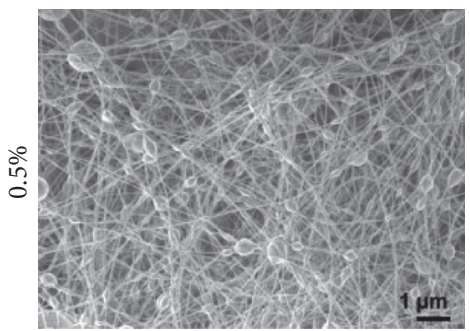

(f)

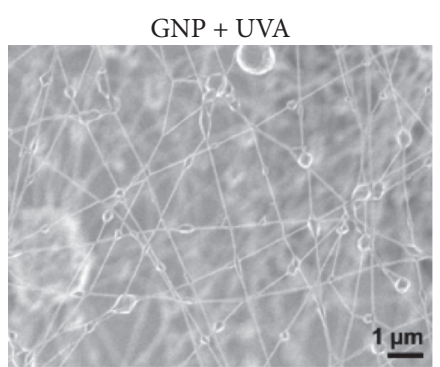

(g)

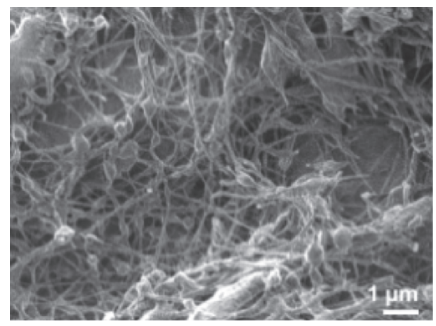

(h)

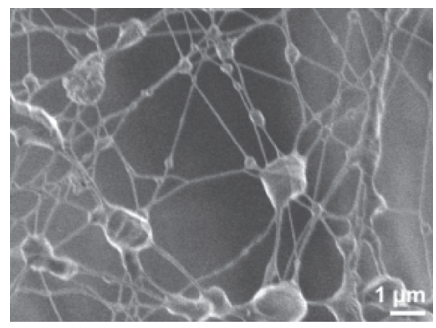

(i)



(j)

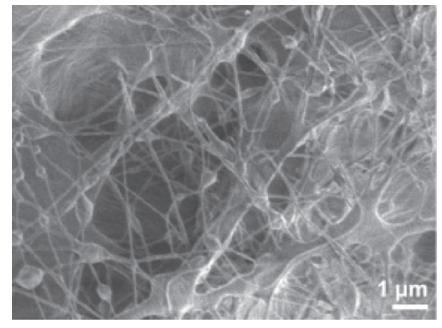

(k)

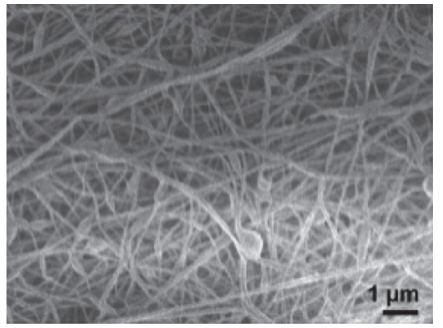

(l)

FIGURE 2: SEM micrographs of the cross-linked S (PEO/CH) fibers at $0.1,0.2,0.3,0.4$, and $0.5 \% \mathrm{v} / \mathrm{v}$ of GNP without or upon UVA irradiation. Scale bars in the inset image correspond to $1 \mu \mathrm{m}, \times 10,0000.5 \mathrm{kV}$. 


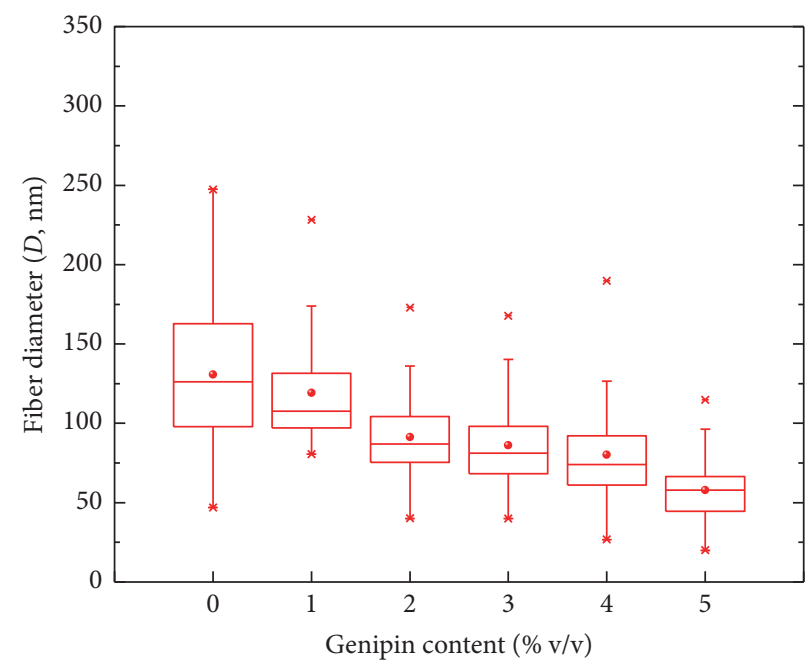

(a)

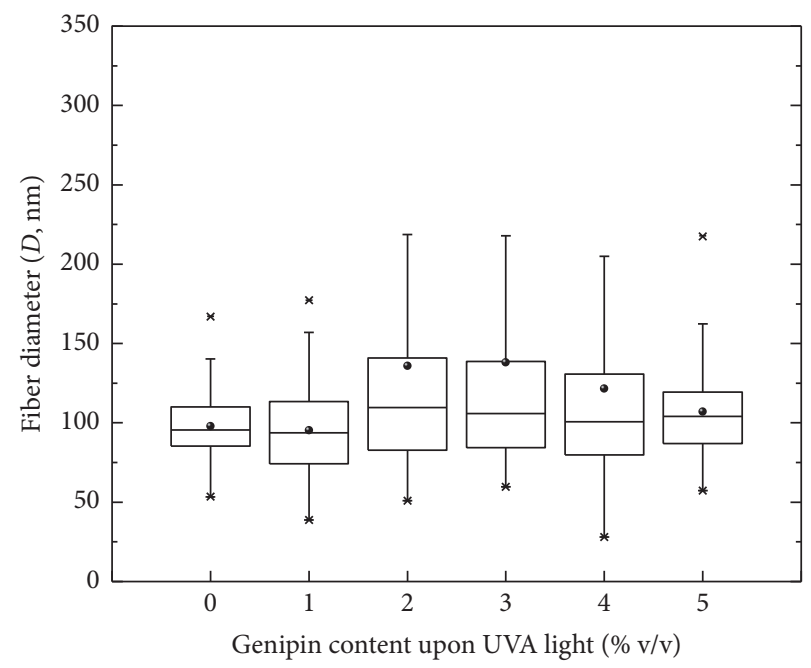

(b)

Figure 3: (a) Fiber diameters at distinct \% v/v GNP content and (b) GNP upon UVA radiation.

is presented in the sample, but, in general, this compound for a given concentration did not strongly affect the morphology. All cross-linked fibers exhibited nanoscale sizes in the $58-159 \mathrm{~nm}$ range, not observing a great effect on the dimension of either the nature of the cross-linker reagent or the content of the reagent, in GTA or TPP case. A more homogeneous morphology of the fibers treated with GNP and GTA compared with the ones treated with TPP was obtained.

Additionally, we compared the photo-cross-linking method by using GNP polymer solutions. In this case, applying UVA light over the ejected polymer jet, the resulting morphology was markedly changed with respect to their equivalents without UVA irradiation. This fact may be explained in terms of photoreaction of GNP; it probably means that either postpolymerization of GNP monomers or an increasing of the extent of cross-linking reaction between GNP onto chitosan moieties can occur [44-46]. To analyze both cases, later studies of FT-IR and ninhydrin assay will be discussed. A thickening on S0.3GNPUV fibers was observed in some areas, forming a spider web-like membrane; regardless of this fact, most of the SXGNPUV membranes scarcely had fibers and a major presence of beads. It is hypothesized that these features resulted from having remaining unreacted genipin molecules promoting the intrachain and/or interchain coupling by means of a genipin after reaction. This hypothesis will be confirmed by further degradation tests, assessing the fiber resistance depending on cross-linking process.

Figure 3(a) shows a nearly linear trend of the mean diameter values versus the content of GNP. At $0.1 \% \mathrm{v} / \mathrm{v}(1 \mathrm{~mol}$ $\mathrm{NH}_{2}: 51 \mathrm{~mol}$ GNP), the fiber diameter was greater (119 \pm $33 \mathrm{~nm}$ ) than those at lower content incorporated $(58 \pm 17 \mathrm{~nm})$, probably because cross-linking altered the polymer chain interactions as a consequence of the decreasing of the free amino groups [47]. As genipin content increases, the mean diameter gradually decreases around $73 \mathrm{~nm}$, around half the size (from 0 to $0.5 \% \mathrm{v} / \mathrm{v}, 0-0.0625 \mathrm{mmol} \mathrm{GNP}$ ). In this sense, the GNP content was a factor that modified the spinnability of the solution, reducing the value dimensions. Here, we can emphasize the importance of examining the fabrication of cross-linked fiber in order to control the mean diameter fiber, therefore manipulating the overall process.

Morphological features and dimensions differ dramatically from the single GNP cross-linked to the GNP crosslinked upon irradiation ones. Mean diameter behavior did not show a decrease, as the GNP content increases, distinct effect was observed (Figure 3(b)); in this case, mean diameter values oscillated around the same interval ( $91 \pm 33-107 \pm 30$ ), exhibiting greater standard deviations. Likewise, when both different methods were combined, an increase of the dripping was observed during the electrospinning process.

3.2. FT-IR Analysis. The typical bands of the polymeric system are described as follows. The absorbance region $3641-3016 \mathrm{~cm}^{-1}$ indicated the presence of stretching $\mathrm{O}-\mathrm{H}$ groups, amine N-H symmetrical vibrations, and inter- and intramolecular hydrogen bonds. A strong band at $2881 \mathrm{~cm}^{-1}$ corresponding to the $\mathrm{C}-\mathrm{H}$ stretch vibration mode was observed, while the broad absorbance band at $1655 \mathrm{~cm}^{-1}$ is assigned to $-\mathrm{NH}_{2}$ and amide groups. Another broad signal at $1564 \mathrm{~cm}^{-1}$ is attributed to the amide III band and symmetric deformation of $\mathrm{NH}_{2}$ groups from chitosan. The band at $1463 \mathrm{~cm}^{-1}$ is assigned to the $\mathrm{CH}_{2}$ vibration from PEO. The band $1456 \mathrm{~cm}^{-1}$ is assigned to the scissors vibration mode of the methylene $-\mathrm{CH}_{2}$ - originated from polymer backbone (PEO and $\mathrm{CH}$ ); the sharp band at $1341 \mathrm{~cm}^{-1}$ corresponds to the methyl $-\mathrm{CH}_{3}$ group deformation mode from PEO. The absorption bands at $1280 \mathrm{~cm}^{-1}$ and $1238 \mathrm{~cm}^{-1}$ originated from $\mathrm{C}-\mathrm{O}-\mathrm{C}$ antisymmetric stretch ( $\mathrm{PEO}$ and $\mathrm{CH})$. A strong band at $1104 \mathrm{~cm}^{-1}$ corresponds to the stretch $\mathrm{C}-\mathrm{O}$ mode.

In addition to the vibrational bands formerly elucidated, the FT-IR spectra of cross-linked electrospun fibers using 


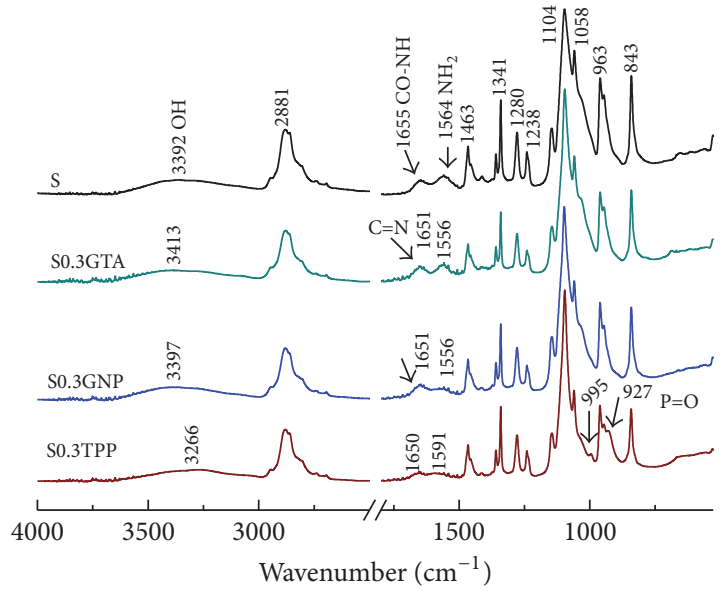

(a)

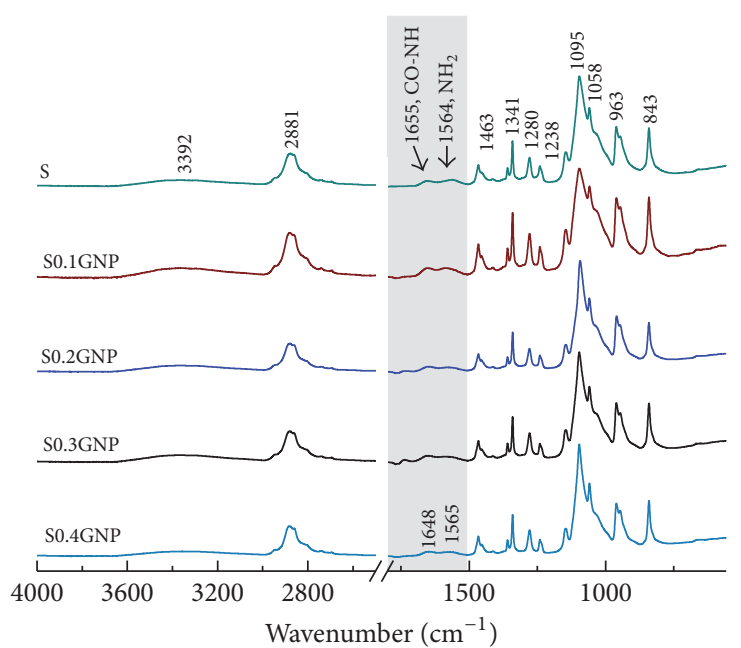

(b)

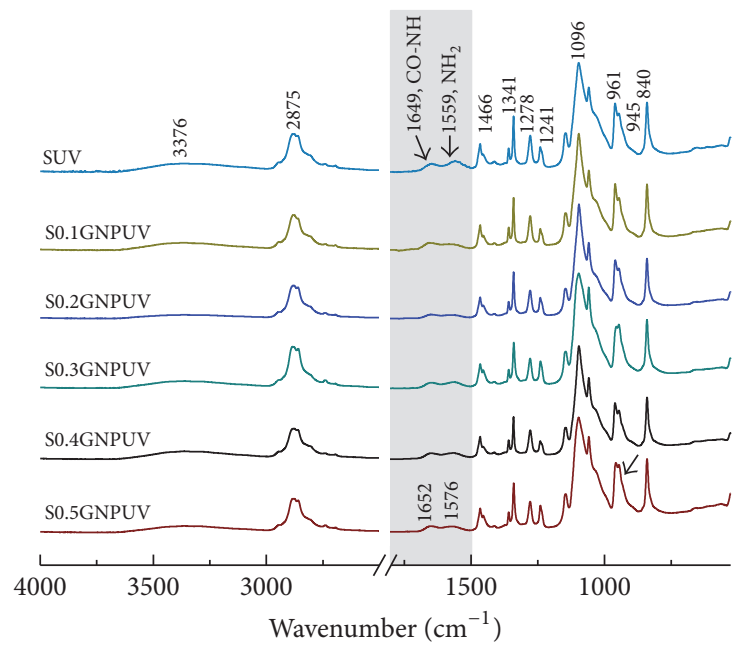

(c)

FIGURE 4: (a) FT-IR spectra of the uncross-linked fiber indicated by S (PEO/CH) and cross-linked fibers: at 0.3\% v/v GTA, GNP, and TPP, respectively. (b) FT-IR spectra of the cross-linked fibers: at 0.1, 0.2, 0.3, and $0.4 \% \mathrm{v} / \mathrm{v}$ GNP. (c) FT-IR spectra of the GNP cross-linked fibers upon UVA irradiation: at $0.1,0.2,0.3,0.4$, and $0.5 \% \mathrm{v} / \mathrm{v}$ GNP.

$0.3 \% \mathrm{v} / \mathrm{v}$ of the three couple agents TPP ( $1 \mathrm{~mol}$ TPP : $28 \mathrm{~mol}$ $\mathrm{NH}_{2}$ ), GNP (1 mol GNP:17 mol $\mathrm{NH}_{2}$ ), and GTA (1 mol GTA : $45 \mathrm{~mol} \mathrm{NH}_{2}$ ) were recorded to analyze the molecular interaction in the chemically modified fiber (Figure 4(a)). One cross-link method employed here was with the asymmetric molecule GNP, which has been known to present two mechanism stages. The reaction begins through initial nucleophilic attack of the amino group from $\mathrm{CH}$ at the carbon atom C-3 of the deoxyloganin aglycone of GNP molecule, to form an intermediate aldehyde $[44,45]$. To confirm that the reaction had proceeded, FT-IR spectrum was analyzed, detecting the decrease at $1564 \mathrm{~cm}^{-1}$ absorption band characteristic of the primary pendant groups of $\mathrm{CH}$ and the increase of the amide band characteristic of GNP-CH [44]. With respect to the GTA, two main mechanisms are possible to cross-link chitosan. According to chemical study, the absence of the absorbance bands in the region 1720-1730 originated by carbonyl groups discards the Michael-type mechanism suggesting the Schiff base mechanism; thus this assumption is confirmed because of the presence of band absorbance at $1655 \mathrm{~cm}^{-1}$ assigned to the $\mathrm{C}=\mathrm{N}$ imine bonds $[25,26]$. Besides, it did not show an identifiable $\mathrm{C}=\mathrm{O}$ stretching band of the unreacted end of the aldehyde between 1700 and $1750 \mathrm{~cm}^{-1}$ and possibly because of the very low concentration used. As expected, the GNP and GTA fibers both displayed the bands corresponding to the amide linkages; this can be verified by the observation of the signals at $1651 \mathrm{~cm}^{-1}$ and $1556 \mathrm{~cm}^{-1}$ (depicted with arrows in Figure 4(a)); on those bands, we note the subtle lowering of the intensity band at $1556 \mathrm{~cm}^{-1}$ $\mathrm{NH}_{2}$, attributable to the reactive amino groups, with less free amines. The appearance of the strong bands at 995 and $927 \mathrm{~cm}^{-1}$ indicated the presence of ions $-\mathrm{PO}_{4}{ }^{2-}$ phosphates units of TPP which are highly involved with the amine protonated of $\mathrm{CH}$ [36], detecting a shift of the $1554 \mathrm{~cm}^{-1}$ band to $1591 \mathrm{~cm}^{-1}$ and a modification of its $\mathrm{H}$-bonds interactions 


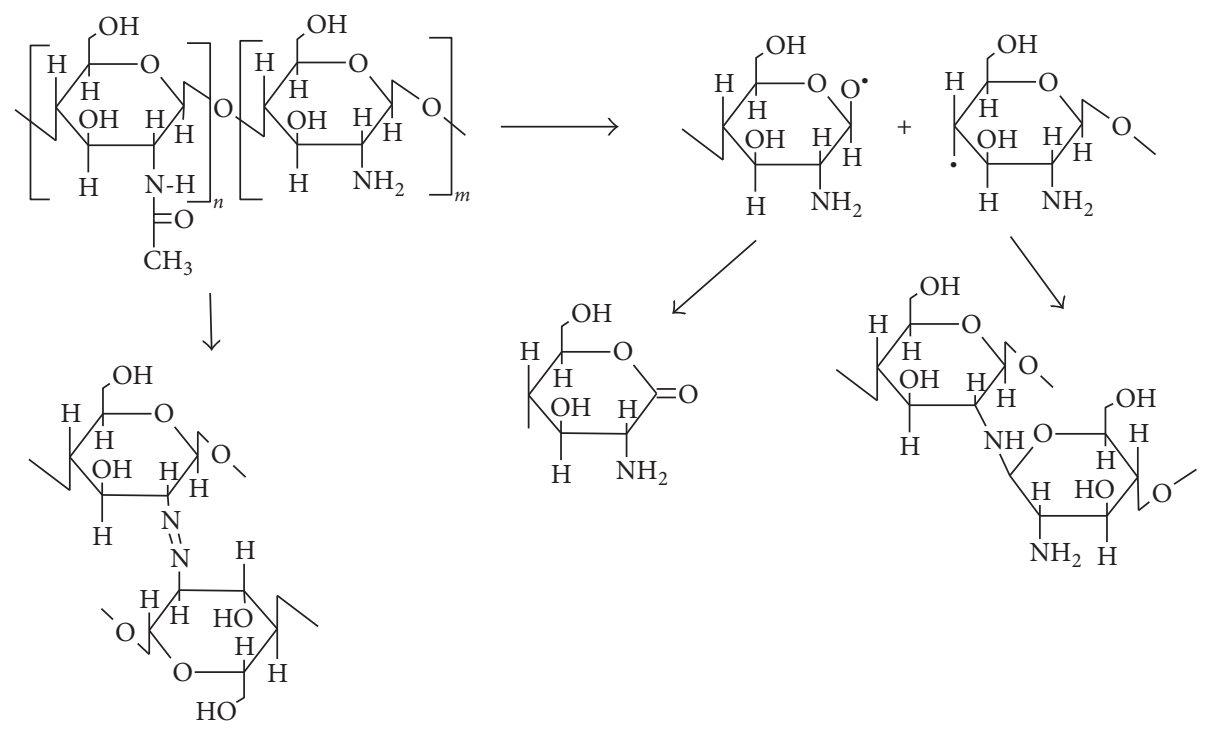

FIgURE 5: Possible mechanism during electrospinning process upon UVA light [34].

from 3392 to $3266 \mathrm{~cm}^{-1}$. Hence it confirmed the ionic cross-linking by electrostatic interaction through ion-pair formation [40].

To study the role of the genipin concentration, we examined cross-linked fibers in specific concentrations of 0.1 , $0.2,0.3,0.4$, and $0.5 \% \mathrm{v} / \mathrm{v}(1: 51,1: 25,1: 17,1: 13$, and $1 \mathrm{~mol}$ GNP : $10 \mathrm{~mol} \mathrm{NH}_{2}$, resp.) and the chemical assessment on them was performed by FT-IR (Figure 4(b)). We can observe two absorption bands at 1648 and $1565 \mathrm{~cm}^{-1}$, attributed to appearance of the secondary amide band and the decreasing of the amine bands, respectively. According to this analysis, a covalent bonding between GNP and CH occurred; however, the presence of amino groups on fibers is still detectable. This presence may be attributed to the reaction extent because this type of covalent coupling takes more than 2 hours, which was our case. Visually, uncross-linked and cross-linked fibers had a white color. Commonly, when the coupling reaction with GNP is completely achieved, blue-fibers are observed [29, 37], along with the absence of the spinnability of the solution. In an attempt to overcome this issue, we took advantage of the in situ process to electrospin cross-linked fibers.

A combining one-step method was implemented to crosslink S fibers, which consisted of two mechanisms, chemical and physical. In addition to the GNP molecule as natural cross-linker, a UVA light (366 nm wavelength) was passed through the polymer jet during the electrospinning process. This irradiated energy could have affected the collected fibers molecularly; nonetheless, we still observe similar FT-R spectra with respect to their counterparts with no molecular alteration observed [48]. However, a shift of the $-\mathrm{NH}_{2}$ vibrational band from 1559 to $1576 \mathrm{~cm}^{-1}$ may be ascribed to the residual energy.

The UVA light transferred to the polymer composite was sufficient to produce changes to the polymeric composites. Chitosan is a very sensitive biopolymer to photolytic degradation $[49,50]$. Exposure of chitosan upon UVA radiation may produce radical formation by random scission on its chain backbone [51], initiating on $\beta$-D- $(1 \rightarrow 4)$ glycosidic bonds, leading to oxidation, giving some carbonyl groups for this stage; thus this can cause further reactions such as degradation and recombination (Figure 5). After the formation of fragments of chitosan during the depolymerization reaction, a cross-linking can be produced by linking of amine groups to pyranose ring. The good water and thermal stabilities of these polymeric materials after UV exposure may be explained by cross-linking after the formation of free radicals [52], which can cause the molecular rearrangement by absorbed energy. Based on the identification of the functional groups which take part, the shifting of the absorptions bands at 1655 and $1564 \mathrm{~cm}^{-1}$ corresponding to $\mathrm{C}=\mathrm{O}$ and $\mathrm{NH}_{2}$, respectively (Figures 4(b) and 4(c)), might confirm the structural changes as a result of these possible mechanisms [34].

3.3. Average Degree of Cross-Linking and Swelling Behavior. Taking the SEM analysis into account, we decided to employ the samples with better morphology, which correspond at $0.2,0.3$, and $0.4 \%$ genipin content $(1: 25,1: 17$, and $1 \mathrm{~mol}$ GNP : $13 \mathrm{~mol} \mathrm{NH}_{2}$, resp.) for further analysis. With the aim of quantifying the extent of cross-linking, the absorbance intensity of the number of free amino groups was estimated by means of spectrophotometric analysis $[53,54]$. The maximum cross-linking efficiency $\% C_{E}$ calculated was of $26 \%$ for $2 \mathrm{~h}$ of coupling reaction with genipin, while the theoretical value estimated was $15.6 \%$. For both membrane systems, as far as GNP is added, greater $\% C_{E}$ values were obtained (Table 2). Although the morphology was highly affected by the addition of physical treatment, the chemical pathway was not apparently precluded or modified.

Whereas a typical uncross-linked $S$ membrane readily dissolves in water, these membranes preserved its wholeness longer, validating that this present method helped acquire membranes with superior physical properties. Swelling behavior suggested a better stability of the membranes treated with GNP and UVA light. The results of this experiment 
TABLE 2: Values of the amount of amino groups and cross-linking efficiency, obtained by ninhydrin assay.

\begin{tabular}{lcc}
\hline Membrane & mol GNP $: \mathrm{mol} \mathrm{NH}_{2}$ & $\% C_{E}$ \\
\hline S0.2GNP & $1: 25$ & 15.6 \\
S0.3GNP & $1: 17$ & 14.0 \\
S0.4GNP & $1: 13$ & 26.0 \\
S0.2GNPUV & $1: 25$ & 8.5 \\
S0.3GNPUV & $1: 17$ & 19.3 \\
S0.4GNPUV & $1: 13$ & 22.5 \\
\hline
\end{tabular}



FIGURE 6: Swelling behavior of the S (PEO/CH) fibers cross-linked with genipin and genipin upon UVA irradiation.

displayed an outstanding retention of water throughout 70 days (Figure 6). Mainly S0.2GNPUV and S0.4GNPUV membranes revealed, for 1 day, 692 and 889 percentage of swelling $\left(\% S_{w}\right)$, respectively. Finally, they were exposed in PBS for 70 days and had a 600 and $296 \% S_{w}$, respectively; but thus S0.4GNP membrane dropped its water uptake to $45 \%$.

3.4. Thermal Properties. In order to verify the earlier results, we analyzed the thermal properties of the membranes. The individual endothermal transition of PEO precursor $\left(T_{m 1}\right)$ appeared at $69.4^{\circ} \mathrm{C}$ (Figure S5). DSC results showed a shift of $T_{m 1}$ to lower temperatures in all samples recorded (Figures $7(\mathrm{a})$ and 7(b)), the SXGNP group being with the lowest values (Table 3 ). This fact might would be explained by the assumption that chitosan prevents the ordered association of PEO chains, affecting directly the crystallinity of PEO and therefore the molecular packing [55]. Such effect is accompanied by the decrease of the melting enthalpies $\left(\Delta H_{m}\right)$ of PEO; consequently those values indicated less crystallinity caused by a higher disorder of the polymer chains within the chitosan network $[56,57]$, varying the $\Delta H_{m}$ values from
$186.7 \mathrm{~kJ} / \mathrm{g}$ (precursor PEO) to $20.8 \mathrm{~kJ} / \mathrm{g}$ (PEO in the crosslinked membrane). The percentage of crystallinity of PEO within the cross-linked membranes was calculated by using

$$
\chi_{C}=\frac{\Delta H_{m}}{\Delta H_{m}^{0}} \times 100,
$$

where $\Delta H_{m}$ is the enthalpy of melting of PEO within the cross-linked fiber and $\Delta H_{m}^{0}$ is the melting enthalpy of $100 \%$ PEO crystal (its value has been taken from the literature of $196.8 \mathrm{~kJ} / \mathrm{g}$ ) [58].

The S0.2GNPUV membrane exhibited a substantially lower value of $\chi_{c}$ found to be equal to $10.5 \%$ contrasting with its individual value as precursor that is $94.8 \%$. In general, it can be said that the high functionality of these membranes depends on its treatment in situ. Similar behavior was observed with the chitosan molecules, where a remarkable shift of its melting temperature $\left(T_{m 2}\right)$ and flatter shape was detected on the set SXGNP (Figure 7(a)). The broadening of the endothermic peak $T_{m 2}$ in SXGNPUV membranes (Figure 7(b)) was more evident in comparison without irradiation and, for this reason, cannot be determined. Chitosan has some crystalline regions as precursor (Figure S5); however, when $T_{m 2}$ is not found (Figure $7(\mathrm{~b})$ ), such phenomenon has been attributed to the rigid-rod polymer backbone owing to strong inter- and/or intramolecular hydrogen bonding and chemical covalent bonds $[56,59]$. Under this argument, the thermal properties indicated a change of $\mathrm{H}$-bond interactions within the membranes, mostly upon applying the chemi$\mathrm{cal} /$ physical treatment, in accordance with the FT-IR spectra (Figure 4(c)) as well.

The thermal stability was evaluated by TGA (Figures 7(c) and $7(\mathrm{~d})$ and Table 3$)$. The degradation temperature $\left(T_{d 2}\right)$ of pure PEO was observed at $372.3^{\circ} \mathrm{C}$ (Figure S6.A), while the degradation curve of pure chitosan registered two stages at 61.6 and $286.1^{\circ} \mathrm{C}\left(T_{d 1}\right)$ (Figure S6.B). On the other hand, $T_{d 1}$ that corresponds to CS of the cross-linked membranes apparently slightly decreased around $7-19^{\circ} \mathrm{C}$, whereas the weight loss percent (wt $\%$ ) decreased from 30 to $6.7-17.5 \mathrm{wt} \%$. This latter effect might be attributed to the cross-linked CS chains that endured more the thermal effect. The $T_{d 2}$ values correspond to the main peaks of these membranes, which were ascribed to PEO. Comparing those $T_{d 2}$ values in the range $386.0-392.8^{\circ} \mathrm{C}$ with pure $\mathrm{PEO}$ at $372.3^{\circ} \mathrm{C}$, an increasing of $T_{d 2}$ was observed after cross-linking [60]. It can be thought that those cross-linked CS chains favored the shifting to higher temperatures approaching to the degradation temperature of PEO. Another reason for relating this assumption is the subtle increasing of the weight loss percent. In general, it may be assumed that such behavior suggests that the polymeric blend produces stronger intermolecular hydrogen bonding between the functional groups of CS and PEO polymers $[61,62]$, at the same time that there are more covalent bonds fashioned by cross-linking. Indeed, these cross-linked fibers improved the thermal stability compared with the individual components [56], thus confirming the effectiveness of these methods performed in this work. 


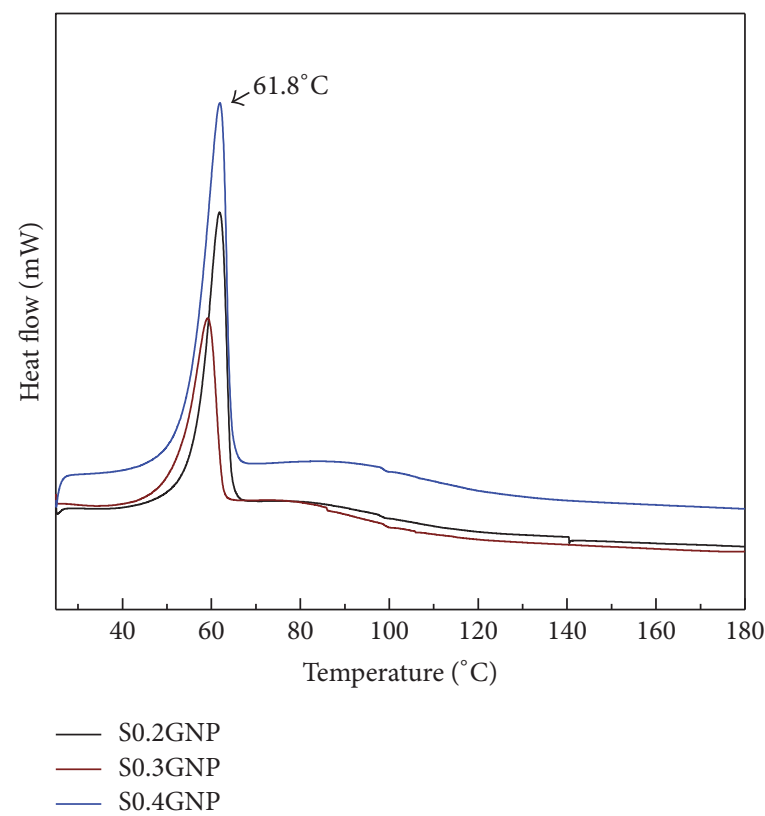

(a)

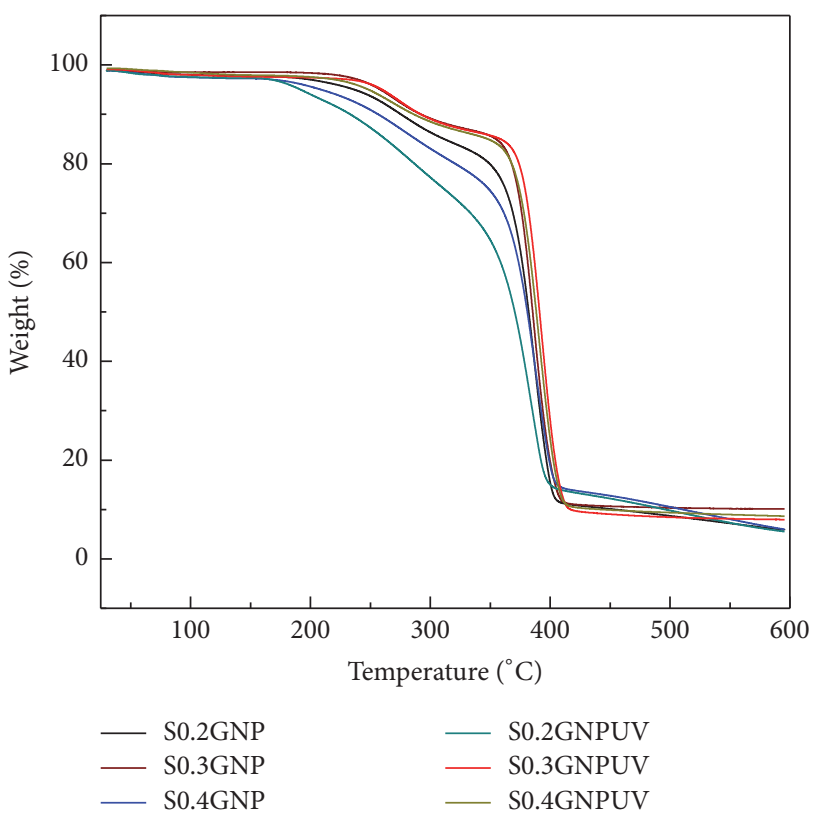

(c)

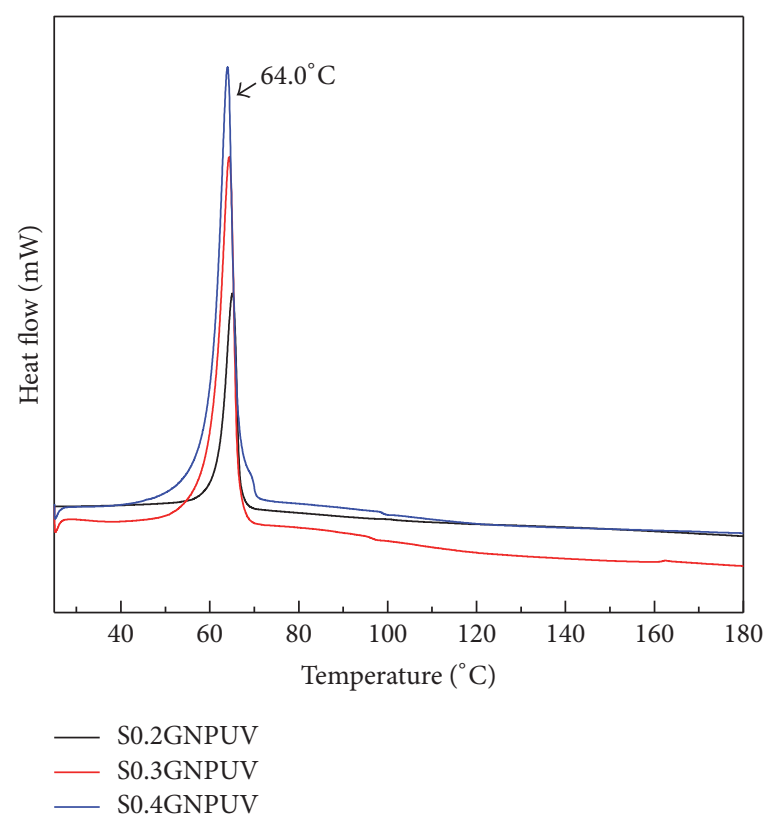

(b)

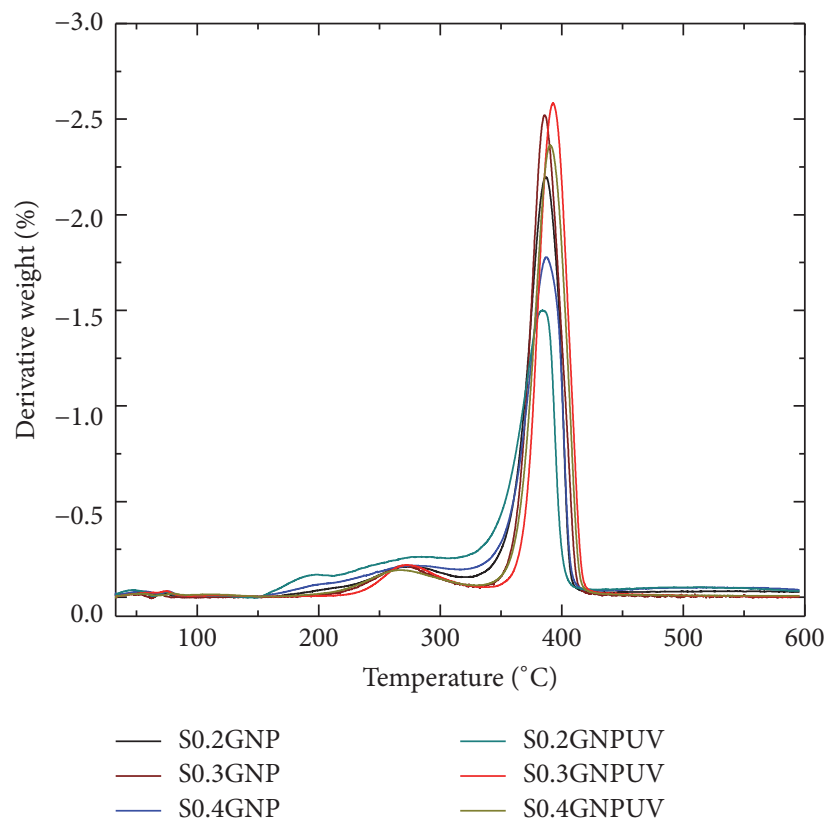

(d)

FIGURE 7: (a) DSC of the cross-linked fibers with genipin and (b) genipin upon UVA irradiation. (c) TGA and (d) DTGA of the cross-linked fibers.

\section{Conclusions}

We successfully fabricated in situ cross-linked membranes varying the chemical reagents (TPP, GTA, and GNP); additionally, a set of fibers was irradiated with $366 \mathrm{~nm}$ wavelength. Chemical study confirmed the appearance of new bonds formed for each chemical pathway. Also, based on FTIR analysis, the use of genipin with/without UVA light did not modify the chemical structure, discarding further degradation. On the other hand, when higher amount of genipin is incorporated, the diameter is smaller, finding the diameter value 2.25 -fold lower, in the case without GNP. When the cross-linked fibers were subjected to UVA energy during the fabrication, large membranes were formed instead of nonwoven fibers; in this sense, a trend of diameter values was not observed. The DSC thermograms confirmed the high disorder of the electrospun macromolecules indicating the chemical cross-linking. All results together suggested that $0.2 \% \mathrm{v} / \mathrm{v}$ GNP ( $1 \mathrm{~mol}$ GNP : $25 \mathrm{NH}_{2}$ ) reacted for $2 \mathrm{~h}$ is ideal for preserving the integrity of chitosan-based membranes, 
TABLE 3: Thermal properties of the cross-linked membranes, assessed by DSC and TGA.

\begin{tabular}{|c|c|c|c|c|c|c|}
\hline \multirow[b]{2}{*}{ Membrane } & \multicolumn{4}{|c|}{ DSC } & \multicolumn{2}{|c|}{ TGA } \\
\hline & $\begin{array}{c}T_{m 1}{ }^{(\mathrm{a})} \\
\left({ }^{\circ} \mathrm{C}\right)\end{array}$ & $\begin{array}{c}T_{m 2}{ }^{(\mathrm{b})} \\
\left({ }^{\circ} \mathrm{C}\right)\end{array}$ & $\begin{array}{c}\Delta H_{m}{ }^{(\mathrm{c})} \\
(\mathrm{kJ} / \mathrm{g})\end{array}$ & $\chi_{C}{ }^{(\mathrm{d})}$ & $\begin{array}{c}T_{d 1}{ }^{(\mathrm{e})} \\
\text { (wt } \% \text { loss) }\end{array}$ & $\begin{array}{c}T_{d 2}^{(\mathrm{f})} \\
\text { (wt\% loss) }\end{array}$ \\
\hline $\mathrm{PEO}$ & 69.4 & - & 186.7 & 94.7 & - & $372.3(53.9)$ \\
\hline $\mathrm{CH}$ & - & 100.9 & 525.2 & - & $\begin{array}{c}61.6(8.1), 286.1 \\
(30.4)\end{array}$ & - \\
\hline S0.2GNP & 61.8 & 82.2 & 42.4 & 21.5 & $277.1(9.3)$ & $386.6(61.2)$ \\
\hline S0.3GNP & 59.2 & 81.2 & 32.1 & 16.3 & $271.5(6.7)$ & $386.0(53.5)$ \\
\hline S0.4GNP & 61.8 & 89.7 & 90.6 & 46.0 & $277.8(12.4)$ & $388.4(60.9)$ \\
\hline S0.2GNPUV & 65.0 & (g) & 20.8 & 10.5 & $279.6(17.5)$ & $384.4(67.4)$ \\
\hline S0.3GNPUV & 64.4 & (g) & 34.2 & 17.4 & $272.6(6.5)$ & $392.8(55.5)$ \\
\hline S0.4GNPUV & 64.0 & (g) & 63.1 & 32.1 & $267.2(7.2)$ & $391.0(55.5)$ \\
\hline
\end{tabular}

${ }^{(\mathrm{a})}$ The melting temperature of $\mathrm{PEO} ;{ }^{(\mathrm{b})}$ the melting temperature of chitosan; ${ }^{(\mathrm{c})}$ the enthalpy of melting of $\mathrm{PEO} ;{ }^{(\mathrm{d})}$ the $\chi_{\mathrm{C}}$ of PEO; ${ }^{(\mathrm{e})}$ the degradation temperature of chitosan; ${ }^{(\mathrm{f})}$ the degradation temperature of PEO; ${ }^{(\mathrm{g})}$ undetectable transition.

with a $<26 \%$ of cross-linking degree. Ultimately, we have demonstrated a favorable effect of UVA irradiation on membranes, enhancing their stability under aqueous and thermal treatments, suggesting changes on their physical properties and its morphology.

\section{Conflicts of Interest}

The authors declare that there are no conflicts of interest regarding the publication of this paper.

\section{Acknowledgments}

The authors acknowledge Universidad Veracruzana for the facilities and thank Josué F. Perzábal Dominguez, Jesús Ponce Crespo, and Angélica Gutierrez-Franco (Universidad Veracruzana) for their technical support. Yanet E. AguirreChagala thanks CONACYT-Mexico (CVU no. 232954) for the financial support (Project no. 29144). This project was partially supported by SEP-PROMEP Project Redes 2015 (UV-CA 314, BUAP-CA 34, and CICATA-IPN) and VIEPBUAP (Project 2017).

\section{References}

[1] F. T. Bosman and I. Stamenkovic, "Functional structure and composition of the extracellular matrix," Journal of Pathology, vol. 200, no. 4, pp. 423-428, 2003.

[2] B.-S. Kim, I.-K. Park, T. Hoshiba et al., "Design of artificial extracellular matrices for tissue engineering," Progress in Polymer Science, vol. 36, no. 2, pp. 238-268, 2011.

[3] Z. G. Chen, P. W. Wang, B. Wei, X. M. Mo, and F. Z. Cui, "Electrospun collagen-chitosan nanofiber: a biomimetic extracellular matrix for endothelial cell and smooth muscle cell," Acta Biomaterialia, vol. 6, no. 2, pp. 372-382, 2010.

[4] S. A. Sell, P. S. Wolfe, K. Garg, J. M. McCool, I. A. Rodriguez, and G. L. Bowlin, "The use of natural polymers in tissue engineering: a focus on electrospun extracellular matrix analogues," Polymers, vol. 2, no. 4, pp. 522-553, 2010.

[5] B. Dhandayuthapani, Y. Yoshida, T. Maekawa, and D. S. Kumar, "Polymeric scaffolds in tissue engineering application: a review,"
International Journal of Polymer Science, vol. 2011, Article ID 290602, 19 pages, 2011.

[6] P. Moutsatsou, K. Coopman, M. B. Smith, and S. Georgiadou, "Conductive PANI fibers and determining factors for the electrospinning window," Polymer (United Kingdom), vol. 77, pp. 143-151, 2015.

[7] C. X. Zhang, X. Y. Yuan, L. L. Wu, Y. Han, and J. Sheng, "Study on morphology of electrospun poly(vinyl alcohol) mats," European Polymer Journal, vol. 41, no. 3, pp. 423-432, 2005.

[8] A. Anitha, S. Sowmya, P. T. S. Kumar et al., "Chitin and chitosan in selected biomedical applications," Progress in Polymer Science, vol. 39, no. 9, pp. 1644-1667, 2014.

[9] M. Z. Elsabee, H. F. Naguib, and R. E. Morsi, "Chitosan based nanofibers, a review," Materials Science and Engineering $C$, vol. 32, no. 7, pp. 1711-1726, 2012.

[10] S. K. Shukla, A. K. Mishra, O. A. Arotiba, and B. B. Mamba, "Chitosan-based nanomaterials: A state-of-the-art review," International Journal of Biological Macromolecules, vol. 59, pp. 46-58, 2013.

[11] A. Willis, A. Chiovitti, T. M. Dugdale, and R. Wetherbee, "Characterization of the extracellular matrix of Phaeodactylum tricornutum (Bacillariophyceae): structure, composition, and adhesive characteristics," Journal of Phycology, vol. 49, no. 5, pp. 937-949, 2013.

[12] J. D. Schiffman and C. L. Schauer, "One-step electrospinning of cross-linked Chitosan fibers," Biomacromolecules, vol. 8, no. 9, pp. 2665-2667, 2007.

[13] M. E. Frohbergh, A. Katsman, G. P. Botta et al., "Electrospun hydroxyapatite-containing chitosan nanofibers crosslinked with genipin for bone tissue engineering," Biomaterials, vol. 33, no. 36, pp. 9167-9178, 2012.

[14] V. T. Tchemtchoua, G. Atanasova, A. Aqil et al., "Development of a chitosan nanofibrillar scaffold for skin repair and regeneration," Biomacromolecules, vol. 12, no. 9, pp. 3194-3204, 2011.

[15] A. E. Donius, M. A. Kiechel, C. L. Schauer, and U. G. K. Wegst, "New crosslinkers for electrospun chitosan fibre mats. Part II: Mechanical properties," Journal of the Royal Society Interface, vol. 10, no. 81, Article ID 20120946, 2013.

[16] N. Reddy, R. Reddy, and Q. Jiang, "Crosslinking biopolymers for biomedical applications," Trends in Biotechnology, vol. 33, no. 6, pp. 362-369, 2015. 
[17] J. D. Schiffman and C. L. Schauer, "Cross-linking chitosan nanofibers," Biomacromolecules, vol. 8, no. 2, pp. 594-601, 2007.

[18] W.-H. Lin and W.-B. Tsai, "In situ UV-crosslinking gelatin electrospun fibers for tissue engineering applications," Biofabrication, vol. 5, no. 3, Article ID 035008, 2013.

[19] A. Lauten, A. Gerhard-Garcia, F. Suhr, J. H. Fischer, H. R. Figulla, and W. Bloch, "Impact of ischemia-reperfusion on extracellular matrix processing and structure of the basement membrane of the heart," PLOS ONE, vol. 9, no. 3, Article ID e92833, 2014.

[20] Q. Jiang, N. Reddy, S. Zhang, N. Roscioli, and Y. Yang, "Waterstable electrospun collagen fibers from a non-toxic solvent and crosslinking system," Journal of Biomedical Materials Research Part A, vol. 101, no. 5, pp. 1237-1247, 2013.

[21] J.-Y. Lai, Y.-T. Li, and T.-P. Wang, "In vitro response of retinal pigment epithelial cells exposed to chitosan materials prepared with different cross-linkers," International Journal of Molecular Sciences, vol. 11, no. 12, pp. 5256-5272, 2010.

[22] J. Kular, J. Tickner, T. Davey et al., "Choline kinase beta is an important regulator of bone homeostasis," Bone, vol. 47, p. S444, 2010.

[23] J. Kawadkar and M. K. Chauhan, "Intra-articular delivery of genipin cross-linked chitosan microspheres of flurbiprofen: Preparation, characterization, in vitro and in vivo studies," European Journal of Pharmaceutics and Biopharmaceutics, vol. 81, no. 3, pp. 563-572, 2012.

[24] A. G. Destaye, C.-K. Lin, and C.-K. Lee, "Glutaraldehyde vapor cross-linked nanofibrous PVA mat with in situ formed silver nanoparticles," ACS Applied Materials \& Interfaces, vol. 5, no. 11, pp. 4745-4752, 2013.

[25] E. S. Costa-Júnior, E. F. Barbosa-Stancioli, A. A. P. Mansur, W. L. Vasconcelos, and H. S. Mansur, "Preparation and characterization of chitosan/poly(vinyl alcohol) chemically crosslinked blends for biomedical applications," Carbohydrate Polymers, vol. 76, no. 3, pp. 472-481, 2009.

[26] J. L. Vondran, W. Sun, and C. L. Schauer, "Crosslinked, electrospun chitosan-poly(ethylene oxide) nanofiber mats," Journal of Applied Polymer Science, vol. 109, no. 2, pp. 968-975, 2008.

[27] A. J. Bavariya, P. Andrew Norowski Jr., K. Mark Anderson et al., "Evaluation of biocompatibility and degradation of chitosan nanofiber membrane crosslinked with genipin," Journal of Biomedical Materials Research - Part B Applied Biomaterials, vol. 102, no. 5, pp. 1084-1092, 2014.

[28] J. Alfredo Uquillas, V. Kishore, and O. Akkus, "Genipin crosslinking elevates the strength of electrochemically aligned collagen to the level of tendons," Journal of the Mechanical Behavior of Biomedical Materials, vol. 15, pp. 176-189, 2012.

[29] K. Sisson, C. Zhang, M. C. Farach-Carson, D. B. Chase, and J. F. Rabolt, "Evaluation of cross-linking methods for electrospun gelatin on cell growth and viability," Biomacromolecules, vol. 10, no. 7, pp. 1675-1680, 2009.

[30] C. Y. Chuang, G. Degendorfer, A. Hammer, J. M. Whitelock, E. Malle, and M. J. Davies, "Oxidation modifies the structure and function of the extracellular matrix generated by human coronary artery endothelial cells," Biochemical Journal, vol. 459, no. 2, pp. 313-322, 2014.

[31] Q. Li, X. Wang, X. Lou et al., "Genipin-crosslinked electrospun chitosan nanofibers: Determination of crosslinking conditions and evaluation of cytocompatibility," Carbohydrate Polymers, vol. 130, pp. 166-174, 2015.

[32] S. Torres-Giner, J. V. Gimeno-Alcañiz, M. J. Ocio, and J. M. Lagaron, "Comparative performance of electrospun collagen nanofibers cross-linked by means of different methods," ACS Applied Materials and Interfaces, vol. 1, no. 1, pp. 218-223, 2009.

[33] C. Chaubaroux, E. Vrana, C. Debry et al., "Collagen-based fibrillar multilayer films cross-linked by a natural agent," Biomacromolecules, vol. 13, no. 7, pp. 2128-2135, 2012.

[34] M. Mucha and A. Pawlak, "Complex study on chitosan degradability," Polimery/Polymers, vol. 47, no. 7-8, pp. 509-516, 2002.

[35] P. Chuysinuan, P. Pavasant, and P. Supaphol, "Preparation and characterization of caffeic acid-grafted electrospun poly(l-lactic acid) fiber mats for biomedical applications," ACS Applied Materials and Interfaces, vol. 4, no. 6, pp. 3031-3040, 2012.

[36] F. Pati, B. Adhikari, and S. Dhara, "Development of chitosantripolyphosphate fibers through $\mathrm{pH}$ dependent ionotropic gelation," Carbohydrate Research, vol. 346, no. 16, pp. 2582-2588, 2011.

[37] F. Mi, H. Sung, S. Shyu, C. Su, and C. Peng, "Synthesis and characterization of biodegradable TPP/genipin co-crosslinked chitosan gel beads," Polymer, vol. 44, no. 21, pp. 6521-6530, 2003.

[38] S. Shenvi, A. F. Ismail, and A. M. Isloor, "Preparation and characterization study of PPEES/chitosan composite membrane crosslinked with tripolyphosphate," Desalination, vol. 344, pp. 90-96, 2014.

[39] M. A. Kiechel and C. L. Schauer, "Non-covalent crosslinkers for electrospun chitosan fibers," Carbohydrate Polymers, vol. 95, no. 1, pp. 123-133, 2013.

[40] S. D. Sarkar, B. L. Farrugia, T. R. Dargaville, and S. Dhara, "Physico-chemical/biological properties of tripolyphosphate cross-linked chitosan based nanofibers," Materials Science and Engineering C, vol. 33, no. 3, pp. 1446-1454, 2013.

[41] C. Tang, C. D. Saquing, J. R. Harding, and S. A. Khan, "In situ cross-linking of electrospun poly(vinyl alcohol) nanofibers," Macromolecules, vol. 43, no. 2, pp. 630-637, 2010.

[42] R. A. A. Muzzarelli, M. El Mehtedi, C. Bottegoni, A. Aquili, and A. Gigante, "Genipin-crosslinked chitosan gels and scaffolds for tissue engineering and regeneration of cartilage and bone," Marine Drugs, vol. 13, no. 12, pp. 7314-7338, 2015.

[43] P. A. Norowski, S. Mishra, P. C. Adatrow, W. O. Haggard, and J. D. Bumgardner, "Suture pullout strength and in vitro fibroblast and RAW 264.7 monocyte biocompatibility of genipin crosslinked nanofibrous chitosan mats for guided tissue regeneration," Journal of Biomedical Materials Research - Part A, vol. 100, no. 11, pp. 2890-2896, 2012.

[44] M. F. Butler, Y. Ng, and P. D. A. Pudney, "Mechanism and kinetics of the crosslinking reaction between biopolymers containing primary amine groups and genipin," Journal of Polymer Science A: Polymer Chemistry, vol. 41, no. 24, pp. 3941-3953, 2003.

[45] F.-L. Mi, S.-S. Shyu, and C.-K. Peng, "Characterization of ringopening polymerization of genipin and $\mathrm{pH}$-dependent crosslinking reactions between chitosan and genipin," Journal of Polymer Science, Part A: Polymer Chemistry, vol. 43, no. 10, pp. 1985-2000, 2005.

[46] F. Mi, H. Sung, and S. Shyu, "Synthesis and characterization of a novel chitosan-based network prepared using naturally occurring crosslinker," Journal of Polymer Science Part A: Polymer Chemistry, vol. 38, no. 15, pp. 2804-2814, 2000.

[47] P. A. Norowski, T. Fujiwara, W. C. Clem et al., "Novel naturally crosslinked electrospun nanofibrous chitosan mats for guided bone regeneration membranes: Material characterization and cytocompatibility," Journal of Tissue Engineering and Regenerative Medicine, vol. 9, no. 5, pp. 577-583, 2015. 
[48] A. Sionkowska, M. Wisniewski, J. Skopinska, C. J. Kennedy, and T. J. Wess, "The photochemical stability of collagen - Chitosan blends," Journal of Photochemistry and Photobiology A: Chemistry, vol. 162, no. 2-3, pp. 545-554, 2004.

[49] S.-M. Wang, Q.-Z. Huang, and Q.-S. Wang, "Study on the synergetic degradation of chitosan with ultraviolet light and hydrogen peroxide," Carbohydrate Research, vol. 340, no. 6, pp. 1143-1147, 2005.

[50] E. Szymańska and K. Winnicka, "Stability of chitosan - A challenge for pharmaceutical and biomedical applications," Marine Drugs, vol. 13, no. 4, pp. 1819-1846, 2015.

[51] J. M. Wasikiewicz, F. Yoshii, N. Nagasawa, R. A. Wach, and H. Mitomo, "Degradation of chitosan and sodium alginate by gamma radiation, sonochemical and ultraviolet methods," Radiation Physics and Chemistry, vol. 73, no. 5, pp. 287-295, 2005.

[52] J. Kowalonek, "Studies of chitosan/pectin complexes exposed to UV radiation," International Journal of Biological Macromolecules, vol. 103, pp. 515-524, 2017.

[53] A. Fiamingo and S. P. Campana-Filho, "Structure, morphology and properties of genipin-crosslinked carboxymethylchitosan porous membranes," Carbohydrate Polymers, vol. 143, pp. 155163, 2016.

[54] M. Friedman, "Applications of the ninhydrin reaction for analysis of amino acids, peptides, and proteins to agricultural and biomedical sciences," Journal of Agricultural and Food Chemistry, vol. 52, no. 3, pp. 385-406, 2004.

[55] S. V. G. Nista, J. Bettini, and L. H. I. Mei, "Coaxial nanofibers of chitosan-alginate-PEO polycomplex obtained by electrospinning," Carbohydrate Polymers, vol. 127, pp. 222-228, 2015.

[56] S. J. Kim, S. R. Shin, and S. I. Kim, “Thermal characterizations of chitosan and polyacrylonitrile semi-interpenetrating polymer networks," High Performance Polymers, vol. 14, no. 3, pp. 309316, 2002.

[57] H. W. Lee, M. R. Karim, J. H. Park et al., "Poly(vinyl alcohol)/chitosan oligosaccharide blend submicrometer fibers prepared from aqueous solutions by the electrospinning method," Journal of Applied Polymer Science, vol. 111, no. 1, pp. 132-140, 2009.

[58] K. A. Narh, L. Jallo, and K. Y. Rhee, "The effect of carbon nanotube agglomeration on the thermal and mechanical properties of polyethylene oxide," Polymer Composites, vol. 29, no. 7, pp. 809-817, 2008.

[59] T. Mitra, G. Sailakshmi, A. Gnanamani, and A. B. Mandal, "Studies on cross-linking of succinic acid with chitosan/collagen," Materials Research, vol. 16, no. 4, pp. 755-765, 2013.

[60] H. Wei, F. Zhang, D. Zhang, Y. Liu, and J. Leng, "Shape-memory behaviors of electrospun chitosan/poly(ethylene oxide) composite nanofibrous membranes," Journal of Applied Polymer Science, vol. 132, no. 37, pp. 42532.1-42532.9, 2015.

[61] C. Tonin, A. Aluigi, C. Vineis, A. Varesano, A. Montarsolo, and F. Ferrero, "Thermal and structural characterization of poly(ethylene-oxide)/keratin blend films," Journal of Thermal Analysis and Calorimetry, vol. 89, no. 2, pp. 601-608, 2007.

[62] I. Kohsari, Z. Shariatinia, and S. M. Pourmortazavi, "Antibacterial electrospun chitosan-polyethylene oxide nanocomposite mats containing ZIF-8 nanoparticles," International Journal of Biological Macromolecules, vol. 91, pp. 778-788, 2016. 



\section{Hindawi}

Submit your manuscripts at

https://www.hindawi.com
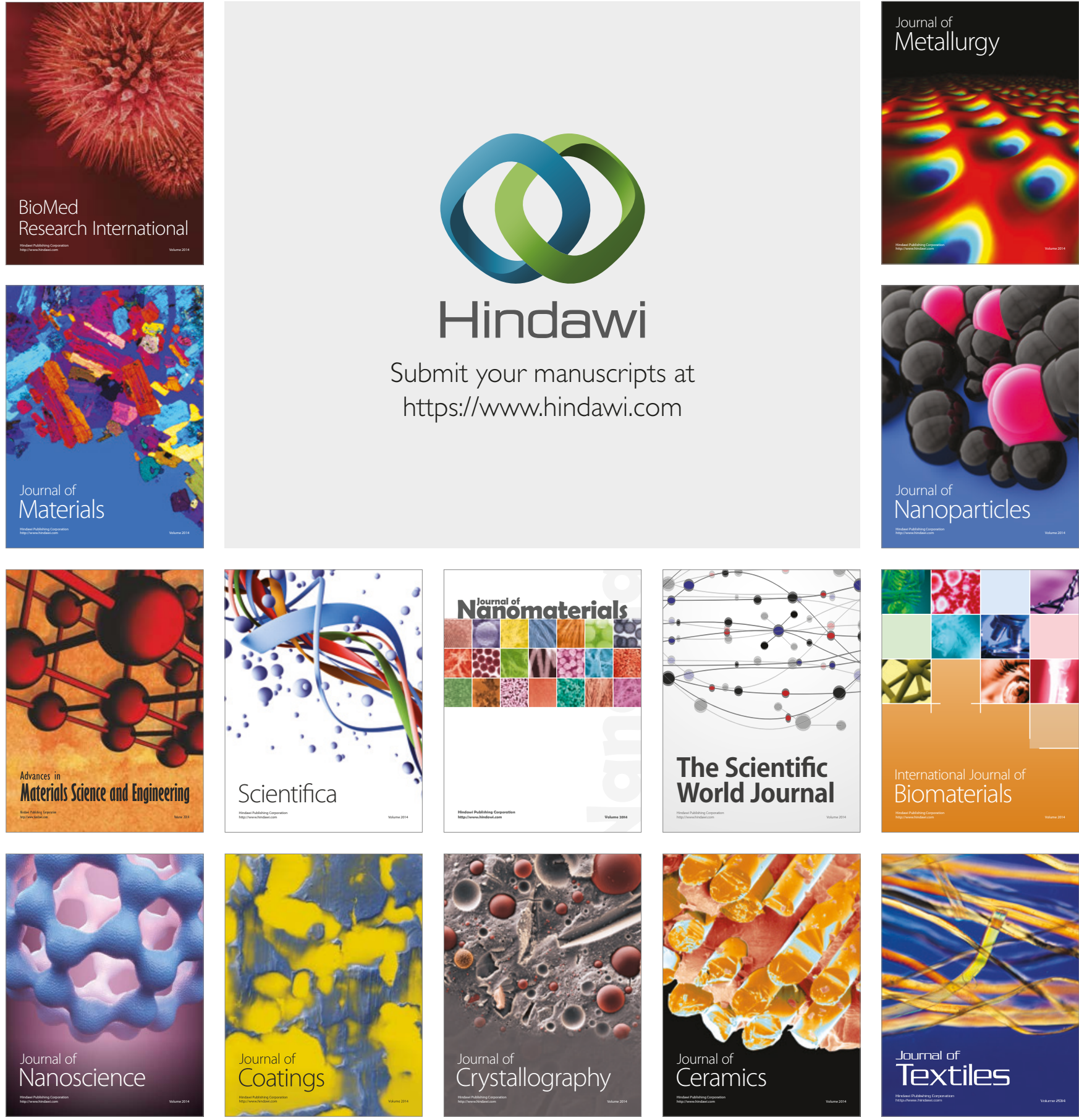

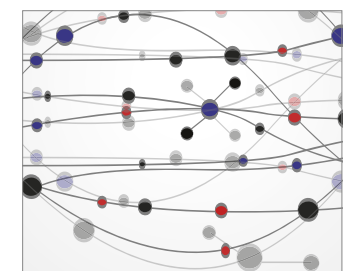

The Scientific World Journal
